\title{
Kinetic analysis and substrate specificity of Escherichia coli dimethyl sulfoxide reductase
}

\author{
Joanne L. Simala-Grant and Joel H. Weiner \\ Author for correspondence: Joel H. Weiner. Tel: +1 403492 2761. Fax: +1 4034920886. \\ e-mail: joel.weiner@ualberta.ca
}

Medical Research Council Group in the Molecular Biology of Membranes, Department of Biochemistry, University of Alberta, Edmonton, Alberta, Canada T6G $2 \mathrm{H} 7$
We have characterized the substrate specificity of dimethyl sulfoxide reductase (DmsABC) of Escherichia coli by determining $\kappa_{m}$ and $k_{\text {cat }}$ values for 22 different substrates. The enzyme has a very broad substrate specificity. The $K_{m}$ values varied 470 -fold, while $\boldsymbol{k}_{\text {cat }}$ values varied only 20 -fold, implicating $\boldsymbol{K}_{\mathrm{m}}$ as the major determinant of $\boldsymbol{k}_{\text {cat }} \boldsymbol{K}_{\mathrm{m}}$ values. Sulfoxides and pyridine $\boldsymbol{N}$-oxide exhibited the lowest $\boldsymbol{K}_{m}$ values, followed by aliphatic $\boldsymbol{N}$-oxides. The $\boldsymbol{k}_{\text {cat }}$ values for these compounds also followed the same pattern. Substitution at the 2 or 3 position of the pyridine $N$-oxide ring had little effect on $\boldsymbol{K}_{\boldsymbol{m}}$, while substitution at the 4 position had a greater effect, and increased $K_{m}$. Negatively charged substrates were poorly accepted. A few compounds that are not $\mathbf{S}$ - or $\boldsymbol{N}$-oxides were also reduced by the enzyme. Most compounds reduced by DmsABC were not toxic to $E$. coli under anaerobic growth conditions, and $E$. coli was able to use many of these compounds anaerobically as terminal electron acceptors in the presence of glycerol. Anaerobic growth on sulfoxides is solely due to DmsABC expression. However, there appears to be another as yet unidentified terminal reductase capable of using pyridine $\boldsymbol{N}$-oxides as terminal electron acceptors.

Keywords: trimethylamine $N$-oxide, molybdoenzyme, anaerobic reductase, pyridine $N$-oxide, $S$ - or $N$-oxide

\section{INTRODUCTION}

Dimethyl sulfoxide (DMSO) reductase (DmsABC) of Escherichia coli is a complex iron-sulfur molybdoenzyme capable of conserving the energy of menaquinol:DMSO oxidoreduction as a proton-motive force across the bacterial membrane (Bilous et al., 1988; Bilous \& Weiner, 1985b; Cammack \& Weiner, 1990; Rothery et al., 1995; Weiner et al., 1992). This constitutive membrane-bound enzyme is composed of three subunits: a catalytic subunit containing molybdenum molybdopterin guanine dinucleotide cofactor (Dms A), an electron transfer subunit containing four [4Fe-4S] clusters (DmsB) and a membrane anchor subunit (DmsC) (Bilous et al., 1988; Cammack \& Weiner, 1990; Rothery \& Weiner, 1991). Characterization of the molybdenum cofactor and $[\mathrm{Fe}-\mathrm{S}]$ centres has proceeded using EPR (Cammack \& Weiner, 1990; Rothery \& Weiner, 1991, 1993) and fluorescence spectroscopy (Rothery et al., 1995), and an understanding of the electron transfer pathway from menaquinol to the

Abbreviations: BV, benzyl viologen; $\mathrm{BVH}^{+}$, reduced benzyl viologen; TMAO, trimethylamine $\mathrm{N}$-oxide. molybdenum cofactor is currently being developed (Trieber et al., 1994).

E. coli is capable of anaerobic growth by glycolysis, or by respiration using a variety of terminal electron acceptors. Respiratory growth of E. coli on several $S$ - and $N$-oxides has been established, and these studies have demonstrated that the terminal reductases Dms ABC and trimethylamine $N$-oxide (TMAO) reductase (TorA) play important roles in this process (Sambasivarao \& Weiner, 1991a). While only $\mathrm{Dms} A \mathrm{BC}$ is responsible for anaerobic growth on DMSO, both DmsABC and TorA are responsible for anaerobic growth on TMAO (Sambasivarao \& Weiner, 1991a). The molybdoenzyme TorA (Mejean et al., 1994; Yamamoto et al., 1986) is inducible (Pascal et al., 1984; Silvestro et al., 1988) and periplasmic (Silvestro et al., 1989). The widespread occurrence in nature of DMSO and TMAO suggests that these compounds may serve as true physiological substrates for the reductases (Barrett \& Kwan, 1985; Kelly \& Baker, 1990; Kiene \& Bates, 1990). The amino acid sequences of DmsABC and TorA are highly homologous, suggesting that the two enzymes might have similar substrate profiles (Mejean et al., 1994). We have found that TorA is restricted in its substrate 
spectrum (Iobbi-Nivol et al., 1996), while DmsABC has a broad substrate specificity (Weiner et al., 1988). However, these experiments examined only a few substrates of DmsABC. Therefore, it has not been possible to make conclusions regarding substrate binding, active site structure and catalysis from our knowledge of substrate specificity.

In this study, we have analysed a variety of $S$ - and $N$ oxides and miscellaneous compounds in order to gain an understanding of the parameters which affect substrate binding and turnover of compounds reduced by Dms ABC. The results obtained are contrasted with the substrate analysis of TorA (Iobbi-Nivol et al., 1996). We have determined the toxicity of a range of DmsABC substrates, and we have monitored the ability of these substrates to serve as anaerobic terminal electron acceptors in wild-type cells, as well as in cells lacking DmsABC and/or TorA. We show that E. coli expresses at least one additional energy-conserving $N$-oxide reductase which is unable to use TMAO or DMSO but utilizes a subset of the compounds tested.

\section{METHODS}

Materials. Potential substrates (Fig. 1) of DmsABC were purchased from Sigma or Aldrich, except for biotin sulfoxide, which was synthesized from biotin (Melville, 1954), and DMSO, which was obtained from Fisher Scientific. For substituted pyridine $N$-oxides, all compounds with substituents in the 2,3 and 4 position were obtained whenever possible.

Strains and plasmids. $E$. coli strains used in this study were: HB101 [supE44 bsdS20 2( $\left.\mathrm{r}_{\mathrm{B}}^{-} \mathrm{m}_{\mathrm{B}}^{-}\right) \operatorname{rec} A 13$ ara-14 proA2 lacY1 galK2 rpsL20 xyl-5 mtl-1] (Boyer \& Roulland-Dussoix, 1969); MC4100 [F- ara D139 (lacI POZY A-argF)U169 rpsL150 rel A1 fb-5301 deoCl PtsF25 rbsR] (Casadaban, 1976); LCB128 [as MC4100; tor $A::$ Mud1 (Ap $\left.\left.{ }^{r}-l a c\right)\right]$ (M. Chippaux, Marseilles, France); DSS401 (as MC4100; $\Delta d m s \mathrm{Km}^{\mathrm{r}}$ ) (Sambasivarao \& Weiner, 1991a); and DSS501 (as LCB128; $\Delta d m s \mathrm{Km}^{\mathrm{r}}$ ) (Sambasivarao \& Weiner, 1991a). For overexpression of DmsABC, bacteria were transformed with pDMS160 (Rothery \& Weiner, 1991). All manipulations of plasmids and strains were carried out essentially as described by Sambrook et al. (1989).

Media and growth conditions. Bacteria were grown anaerobically on minimal media as indicated previously by Bilous \& Weiner (1985a), with the following exceptions. Peptone $(0.16 \%)$ was substituted for Casamino acids, and streptomycin sulfate was not included in the growth medium. Arginine was included at a final concentration of $0.005 \%$ as necessary. When appropriate, $50-100 \mu \mathrm{g}$ ampicillin $\mathrm{ml}^{-1}$ and $40 \mu \mathrm{g}$ kanamycin $\mathrm{ml}^{-1}$ were included in the growth medium. The ability of $S$ - and $N$-oxides to sustain growth on glycerol minimal media was tested by growing cells in sealed screw-capped tubes containing a small air bubble to allow mixing using a continuously rotating wheel. Quantitative growth experiments were performed in Klett flasks (Sambasivarao \& Weiner, 1991a).

Assessment of the toxicity of DmsABC substrates by inhibition of anaerobic growth of $\boldsymbol{E}$. coli. HB101 grown overnight in LB was used as a $1 \%$ inoculum for $3 \mathrm{ml}$ of unsolidified LB top agar $(0.7 \%)$. This sample was mixed and poured onto LB agar plates. Sterilized filters were dipped into filter-sterilized substrate to the point of saturation and placed on LB agar plates overlaid with LB top agar containing bacteria. All potential Dms ABC substrates were used at $300 \mathrm{mM}$, except 3-amidopyridine $N$-oxide $(100 \mathrm{mM})$. Platinum catalyst and plates were placed in anaerobic jars that were subsequently repeatedly evacuated and filled with $\mathrm{H}_{2} / \mathrm{CO}_{2}(10: 90, \mathrm{v} / \mathrm{v})$. After $72 \mathrm{~h}$ at $37^{\circ} \mathrm{C}$, the diameter of the zone of clearing (absence of growth) around the substrate-soaked filters was measured. Fumarate and nitrate were used as non-toxic controls. $\mathrm{K}_{2} \mathrm{CrO}_{4}$ and ampicillin were used as positive toxic controls.

Purification of DmsABC. HB101(pDMS160) was grown in 191 carboys and harvested using a Pellicon membranes system as indicated previously (Weiner et al., 1988). The cell paste was resuspended in buffer (Rothery \& Weiner, 1991), and everted envelopes were prepared as indicated by Bilous \& Weiner (1985a). The membrane fraction was extracted with Triton X100 as indicated by Cammack \& Weiner (1990). DmsABC was purified from solubilized membrane proteins on a DEAEcellulose (Whatman DE-52) column as indicated previously (Weiner et al., 1988), except that a $0-0.2 \mathrm{M} \mathrm{KCl}$ gradient was used, equivalent to ten column volumes, or on a DEAESepharose CL-6B column with a $50-300 \mathrm{mM} \mathrm{NaCl}$ gradient equivalent to two column volumes.

Kinetic analysis. Substrate-dependent oxidation of the electron donor, reduced benzyl viologen $\left(\mathrm{BVH}^{\circ+}\right)$, was monitored at $570 \mathrm{~nm}$ using a Gilford 250 spectrophotometer. MOPS $(50 \mathrm{mM} ; \mathrm{pH} \mathrm{7.0)}$ was used as the buffer for all assays, and electron acceptor (substrate) was varied as necessary. For opencuvette (non-stoppered) assays, using degassed MOPS buffer, benzyl viologen (BV) was used at a final concentration of $0.2 \mathrm{mM}\left(\varepsilon\right.$ of $\mathrm{BVH}^{++}=7.8 \times 10^{3} \mathrm{lmol}^{-1} \mathrm{~cm}^{-1}$ ) and sodium dithionite at a concentration of $0.33 \mathrm{mM}$. The final assay volume was kept constant, with the ordered addition of BV, substrate, dithionite and enzyme. Closed-cuvette assays (stoppered) were performed using degassed buffer that was subsequently bubbled with nitrogen. Buffer was transferred to a cuvette, which was then stoppered. Hamilton syringes were used for ordered addition as above. A stable baseline was confirmed prior to addition of enzyme. For closed-cuvette assays, BV was used at a final concentration of $0.2 \mathrm{mM}$, and dithionite was added to approximately $0 \cdot 1 \mathrm{mM}$, to give an absorbance of about $1 \cdot 0$. Closed-cuvette assays were used unless indicated in the text. All assays were performed at $30^{\circ} \mathrm{C}$ using equilibrated buffer and a jacketed cuvette holder, except for the comparison of open- and closed-cuvette assays and membrane-bound, solubilized and purified enzyme, which were performed at $25^{\circ} \mathrm{C}$. One unit of enzyme activity corresponds to $1 \mu \mathrm{mol} \mathrm{BVH}{ }^{\circ+}$ oxidized $\min ^{-1}$, or $0.5 \mu \mathrm{mol} S$ - or $N$-oxide reduced $\mathrm{min}^{-1}$. Between three and nine assays were performed at each substrate concentration, and five to eight different substrate concentrations were examined to determine each $K_{\mathrm{m}}$. The values used were means. In all cases, the standard deviation of the mean was less than $10 \%$. Whenever possible, a range of substrate concentrations was chosen that varied from at least two times less than the $K_{\mathrm{m}}$ to five times greater than the $K_{\mathrm{m}}$. This range of substrate concentration could not be achieved in some instances, due to limitations resulting from the minimum concentration of substrate that can be used in the assay, or substrate inhibition. We ensured that only a small fraction of the substrate was utilized during the course of the experiment. $K_{\mathrm{m}}$ and $V_{\max }$ values were determined from Eadie-Hofstee plots (Fersht, 1977). The $K_{m}$ values obtained are apparent $K_{\mathrm{m}}$ values using a saturating concentration of BV. $k_{\text {cat }}$ values were determined by estimating the enzyme purity from PAGE analysis, as indicated below. Assays were performed on freshly diluted enzyme that was previously beaded into liquid nitrogen and stored at $-70^{\circ} \mathrm{C}$. The diluted sample was stored on ice and used during the day to obtain reproducible results. Compounds found not to be substrates were tested for their ability to inhibit the transfer of electrons from reduced DmsABC 
(a) Pyridine $\mathrm{N}$-oxides

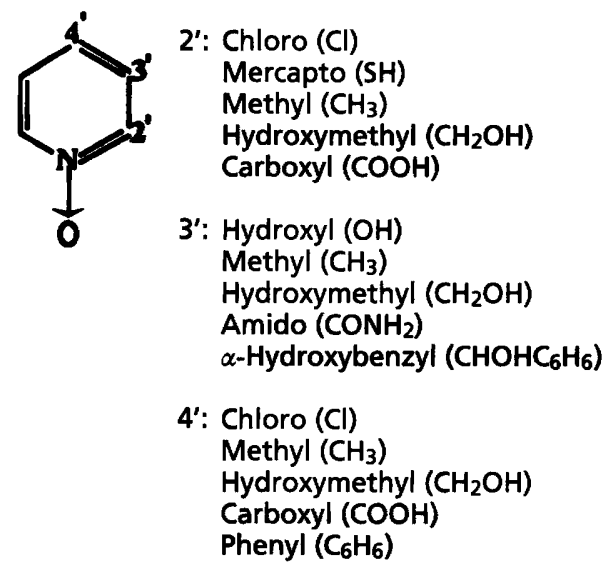

(b) Aliphatic $\mathrm{N}$-oxides

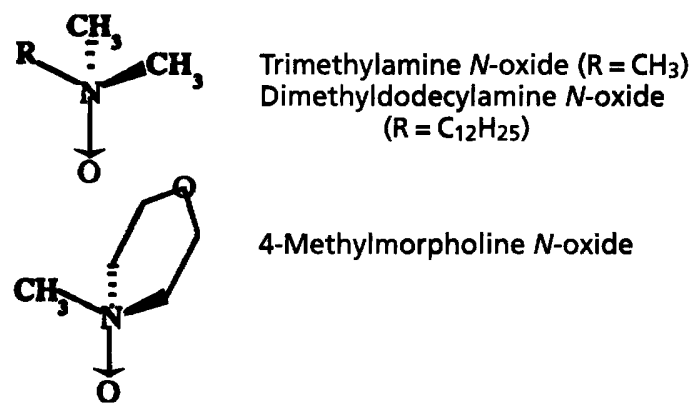

(c) Sulfoxides
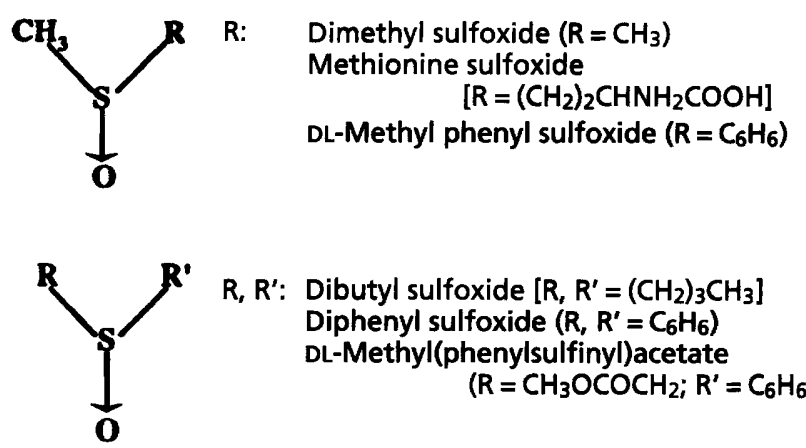

$R, R^{\prime}$ : Dibutyl sulfoxide $\left[R, R^{\prime}=\left(\mathrm{CH}_{2}\right)_{3} \mathrm{CH}_{3}\right]$ Diphenyl sulfoxide $\left(R, R^{\prime}=\mathrm{C}_{6} \mathrm{H}_{6}\right)$ DL-Methyl(phenylsulfinyl)acetate $\left(\mathrm{R}=\mathrm{CH}_{3} \mathrm{OCOCH}_{2} ; \mathrm{R}^{\prime}=\mathrm{C}_{6} \mathrm{H}_{6}\right)$<smiles>O=C1CCCC1</smiles>

Tetramethylene sulfoxide
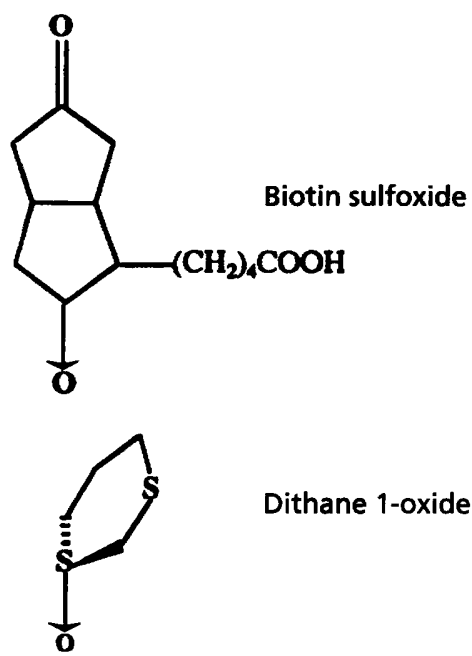

Dithane 1-oxide

Fig. 1. Structures of the $S$ - and $\mathrm{N}$-oxides used in this study.

to TMAO, by inclusion in the cuvette at a concentration equal to that of TMAO.

Analytical techniques. Protein concentrations were determined by the method of Markwell et al. (1978). SDS-PAGE was carried out according to Laemmli (1970), and gels were stained (Lemire et al., 1982) and scanned with a Joyce-Loebel Chromoscan 3 densitometer to determine the purity of DmsABC. DmsABC bands were confirmed by Western blotting (Sambasivarao \& Weiner, 1991b).

\section{RESULTS}

\section{Dithionite inhibits DmsABC}

Several assays have been developed to monitor the activity of terminal reductases, including DmsABC. The most widely used is a spectrophotometric assay which measures the substrate-dependent oxidation of $\mathrm{BVH}^{*+}$. Both opencuvette (Oren \& Truper, 1990; Sambasivarao \& Weiner, 1991b; Yamamoto et al., 1989) and closed-cuvette
(Cecchini et al., 1986; Neumann \& Simon, 1984) versions of this assay have been developed (see below). We examined the kinetic parameters of DmsABC with TMAO using both assays. With membrane-bound Dms ABC, the $K_{\mathrm{m}}$ values determined using either assay were similar (open cuvette, $32.3 \mathrm{mM}$; closed cuvette, $25.4 \mathrm{mM}$ ). However, when assays were carried out with purified DmsABC, we noted at least a fourfold higher apparent $K_{\mathrm{m}}$ value for TMAO under open-cuvette conditions (open cuvette, $71.6 \mathrm{mM}$; closed cuvette, $18.0 \mathrm{mM}$ ). Similar results were obtained for all substrates tested (data not shown). The closed cuvette $K_{\mathrm{m}}$ for purified DmsABC was close to the membrane-bound value. The $k_{\text {cat }}$ values were depressed by about $15 \%$ under open-cuvette conditions. When the assays were performed with freshly solubilized Dms ABC, an intermediate $K_{\mathrm{m}}(42 \mathrm{mM})$ for TMAO was obtained utilizing the open-cuvette assay, potentially resulting from enzyme with mixed stability. 


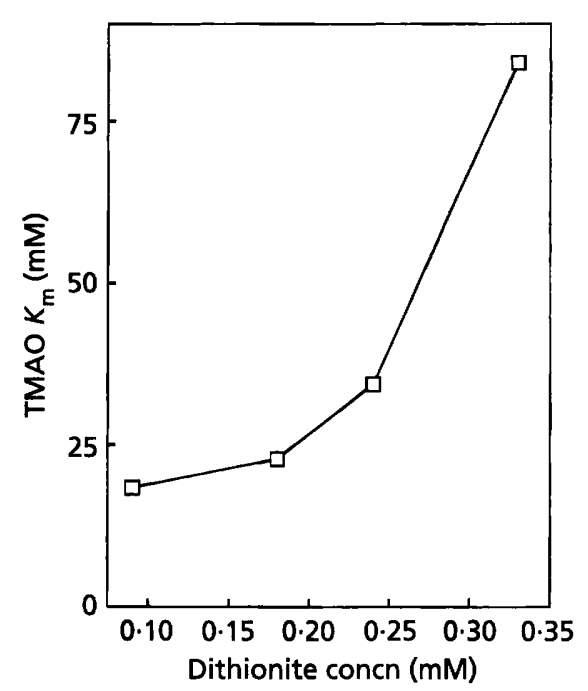

Fig. 2. $K_{\mathrm{m}}$ for TMAO varies with dithionite concentration. DmsABC was assayed in the closed-cuvette assay as indicated in Methods, with increasing concentrations of dithionite added to the cuvette.

Further investigation of assay conditions indicated that the apparent $K_{\mathrm{m}}$ differences resulted from the dithionite used to produce $\mathrm{BVH}^{+}$. The open-cuvette assay requires an excess of dithionite to BV, whereas the closed-cuvette assay excludes oxygen (using degassed and nitrogenbubbled buffer in a stoppered cuvette), and uses only enough dithionite to reduce a portion of the BV. To demonstrate that dithionite is responsible for the increase in apparent $K_{\mathrm{m}}$ observed when using the open-cuvette assay, the closed-cuvette assay was performed but altered to use increasing concentrations of dithionite, up to the value normally used in the open-cuvette assay. Fig. 2 shows that as the dithionite concentration increases, the apparent $K_{\mathrm{m}}$ increases. However, the apparent $K_{\mathrm{m}}$ reaches a plateau at lower dithionite concentrations, and at a value approximately equivalent to that determined by closedcuvette assay conditions. This plateau in apparent $K_{\mathrm{m}}$ suggests that the closed-cuvette assay is more appropriate for accurate kinetic analysis. Dithionite appears to approximate a competitive inhibitor, as excess substrate can reverse the effect (data not shown). It was not possible to quantitate this inhibition because of assay constraints. We found that the product of dithionite oxidation, sodium bisulfite, was also an inhibitor of DmsABC, but the inhibition observed under our assay conditions was not due to bisulfite, as half-maximal inhibition for bisulfite occurred at $25 \mathrm{mM}$, and a maximal level of only $0.66 \mathrm{mM}$ was present in the cuvette.

The interaction of dithionite with the enzyme explains the order of addition effects previously observed (J. H. Weiner \& D. MacIssac, unpublished results). $S$ - or $N$ oxide substrates must be present before the enzyme comes into contact with dithionite to prevent depressed $k_{\text {cat }}$ values, suggesting that the oxide substrate protects the enzyme from dithionite inactivation.

\section{Utilization of $\mathbf{N}$-oxides by DmsABC}

A wide variety of $\mathrm{N}$-oxides (Fig. 1) were examined for their ability to act as electron acceptors. The apparent $K_{\mathrm{m}}$ and $k_{\text {cat }}$ values obtained under closed-cuvette conditions are listed in Table 1.

Examination of a group of substituted pyridine $N$-oxides led to some interesting findings about substrate specificity. Unsubstituted pyridine $N$-oxide has a $K_{\mathrm{m}}$ of $0.094 \mathrm{mM}$. Substitution at the 2 position did not appear to alter $K_{\mathrm{m}}$ or $k_{\text {cat }}$ significantly. Hydrophobic substituents, $\mathrm{CH}_{3}$, $\mathrm{CH}_{2} \mathrm{OH}$ and amido groups are preferred (low $K_{\mathrm{m}}$ ), whereas hydroxy and carboxy groups are not accepted, resulting in lower $k_{\text {cat }}$ and very high $K_{\mathrm{m}}$ values. Substitution in the 4 position generally increased the $K_{\mathrm{m}}$ $(0.25-0.5 \mathrm{mM})$, but had little effect on $k_{\text {cat }}$, resulting in intermediate $k_{\text {cat }} / K_{\mathrm{m}}$ values.

The $K_{\mathrm{m}}$ and inhibition characteristics of 2-hydroxymethylpyridine $N$-oxide were not determined due to the ability to accept electrons directly from $\mathrm{BVH}^{\circ+}$ at high substrate concentrations.

Only a few aliphatic $N$-oxides were available. 4-Methylmorpholine $N$-oxide and TMAO have relatively low $k_{\text {cat }} / K_{\mathrm{m}}$ values. They have substantially higher turnover numbers compared to the other compounds tested, and substantially higher $K_{\mathrm{m}}$ values. The detergent dimethyldodecylamine $N$-oxide was a reasonable substrate, although this compound forms micelles at a concentration of $2.1 \mathrm{mM}$ (Neugebauer, 1990). The $K_{\mathrm{m}}$ was lower than the critical micelle concentration, but there was no break in the Eadie-Hofstee plot at the critical micelle concentration, suggesting that DmsABC is capable of reducing substrate that is part of a micelle. The $K_{\mathrm{m}}$ for dimethyldodecylamine $N$-oxide was substantially lower than for the other aliphatic $N$-oxides, possibly due to multiple interactions between the dodecyl sidechain and the enzyme, or possibly due to partitioning of substrate into the Triton X-100/protein micelles.

\section{Utilization of S-oxides}

In general, the sulfoxides had similar $K_{\mathrm{m}}$ values to that of pyridine $N$-oxide and those substituted in the 2 and 3 position, and $k_{\text {cat }}$ values near 100 (Table 2). Because the sulfoxides have lower $k_{\text {cat }}$ values than pyridine $N$-oxide compounds, some of the substituted pyridine $N$-oxides are the best substrates on the basis of $k_{\text {cat }} / K_{\mathrm{m}}$ values.

The substrates DL-methyl phenyl sulfoxide and DLmethionine sulfoxide present the enzyme with different enantiomers. At this time, it is unknown which enantiomers are utilized by DmsABC. This question is being examined by polarimetric analysis.

\section{Utilization of miscellaneous substrates}

Bromate and chlorate exhibited measurable $k_{\text {cat }}$ values of 401 and $7 \cdot 3 \mathrm{~s}^{-1}$, respectively. The $K_{\mathrm{m}}$ for bromate was $31.3 \mathrm{mM}$ and the $k_{\text {cat }} / K_{\mathrm{m}}$ was $12 \cdot 8 \mathrm{~s}^{-1} \mathrm{mM}^{-1}$. It was not possible to calculate a $K_{\mathrm{m}}$ value for chlorate, due to the 
Table 1. Kinetic parameters for $\mathrm{N}$-oxide substrates of DmsABC, and their ability to support or inhibit anaerobic growth of $E$. coli in the presence of glycerol

All assays were performed using the closed-cuvette assay. $K_{\mathrm{m}}$ values were calculated for those substrates with a reasonable $k_{\text {cat }}$. For those compounds where $K_{\mathrm{m}}$ values were not determined, $k_{\text {cat }}$ values were estimated using excess substrate. Anaerobic growth on these compounds $(30 \mathrm{mM})$ in the presence of glycerol was assessed visually as no growth $(-)$, very poor growth $(+/-)$, growth $(+)$ or good growth $(++)$. Bacteria grown in minimal media with no terminal electron acceptor were used as the negative control, and with fumarate as the positive control. ND, Not determined.

\begin{tabular}{|c|c|c|c|c|c|}
\hline Substrate & $\underset{\left(\mathrm{s}^{-1} \mathrm{mM}^{-1}\right)}{k_{\mathrm{cot}} / K_{\mathrm{m}}}$ & $\begin{array}{c}K_{\mathrm{m}} \\
(\mathrm{mM})\end{array}$ & $\begin{array}{c}k_{\mathrm{cat}} \\
\left(\mathrm{s}^{-1}\right)\end{array}$ & Growth & $\begin{array}{c}\text { Growth } \\
\text { inhibition }\end{array}$ \\
\hline 2-Chloropyridine $N$-oxide & 7130 & $0 \cdot 043$ & 307 & ++ & No \\
\hline 3-Amidopyridine $N$-oxide & 5280 & $0 \cdot 045$ & 237 & ++ & No \\
\hline 3-Methylpyridine $N$-oxide & 2600 & 0.089 & 231 & ++ & No \\
\hline 2-Methylpyridine $N$-oxide & 2690 & 0.092 & 247 & ++ & No \\
\hline 3-Hydroxymethylpyridine $N$-oxide & 2280 & 0.094 & 214 & ++ & No \\
\hline Pyridine $N$-oxide & 2580 & 0.094 & 243 & ++ & No \\
\hline $3 \alpha$-Hydroxybenzylpyridine $N$-oxide & 1450 & $0 \cdot 158$ & 229 & - & No \\
\hline 4-Phenylpyridine $N$-oxide & 1205 & $0 \cdot 246$ & 297 & - & No \\
\hline 4-Hydroxymethylpyridine $N$-oxide & 607 & $0 \cdot 372$ & 226 & ++ & No \\
\hline 4-Methylpyridine $N$-oxide & 592 & $0 \cdot 452$ & 268 & ++ & No \\
\hline 4-Chloropyridine $N$-oxide & 413 & 0.513 & 212 & $+/-$ & No \\
\hline Dimethyldodecylamine $N$-oxide & 287 & $0 \cdot 83$ & 239 & - & Yes \\
\hline 3-Hydroxypyridine $N$-oxide & 135 & $3 \cdot 17$ & 429 & ++ & No \\
\hline 3-Carboxypyridine $N$-oxide & 34 & $4 \cdot 94$ & 168 & ++ & No \\
\hline 4-Methylmorpholine $N$-oxide & 52 & $11 \cdot 1$ & 573 & ++ & No \\
\hline TMAO & 59 & $20 \cdot 2$ & 1203 & ++ & No \\
\hline 2-Hydroxymethylpyridine $N$-oxide & ND & ND & $89 \cdot 3$ & + & ND \\
\hline 4-Carboxypyridine $N$-oxide & ND & ND & $30 \cdot 3$ & ++ & No \\
\hline 2-Mercaptopyridine $N$-oxide & ND & ND & $8 \cdot 0$ & - & No \\
\hline 2-Carboxypyridine $N$-oxide & ND & ND & $8 \cdot 0$ & $+1-$ & No \\
\hline
\end{tabular}

Table 2. Kinetic parameters for S-oxide substrates of DmsABC, and their ability to support or inhibit anaerobic growth of $E$. coli in the presence of glycerol

Measurements are as described in the legend to Table 1. All assays were performed using closed cuvettes.

\begin{tabular}{|lccccc|}
\hline Substrate & $\begin{array}{c}\boldsymbol{k}_{\text {cat }} / \boldsymbol{K}_{\mathbf{m}} \\
\left(\mathbf{s}^{-1} \mathbf{m M}^{-1}\right)\end{array}$ & $\begin{array}{c}\boldsymbol{K}_{\mathbf{m}} \\
(\mathbf{m M})\end{array}$ & $\begin{array}{c}\boldsymbol{k}_{\text {cat }} \\
\left(\mathbf{s}^{-1}\right)\end{array}$ & Growth & Inhibition \\
\hline Tetramethylene sulfoxide & 2080 & $0 \cdot 06$ & 119 & ++ & No \\
Methionine sulfoxide & 663 & $0 \cdot 09$ & $61 \cdot 1$ & ++ & No \\
DL-Methyl phenyl sulfoxide & 483 & $0 \cdot 21$ & $99 \cdot 6$ & + & No \\
DMSO & 455 & $0 \cdot 18$ & $79 \cdot 9$ & ++ & No \\
Dithane 1-oxide & ND & ND & $28 \cdot 4$ & ND & No \\
Dibutyl sulfoxide & ND & ND & $<4$ & - & No \\
Biotin sulfoxide & ND & ND & $<4$ & $+/-$ & No \\
DL-Methyl(phenylsulfinyl)acetate & ND & ND & $<4$ & - & No \\
Diphenyl sulfoxide & ND & ND & $<4$ & - & Yes \\
\hline
\end{tabular}

low $k_{\text {cat }}$. Interestingly, hydroxylamine $\left(K_{\mathrm{m}} 47.5 \mathrm{mM}, k_{\text {cat }}\right.$ $\left.431 \mathrm{~s}^{-1}\right)$ and diethylhydroxylamine $\left(k_{\text {eat }}>389 \mathrm{~s}^{-1}\right)$ were substrates, although high concentrations of hydroxylamine inhibited enzyme activity. The $K_{\mathrm{m}}$ for diethylhydroxylamine could not be determined, since it accepts electrons directly from $\mathrm{BVH}^{++}$at high substrate concen- trations. Diethylhydroxylamine was capable of supporting anaerobic growth. Adenosine $\mathrm{N}$-oxide was not used by DmsABC when MOPS was used as the buffer. However, when $50 \mathrm{mM}$ potassium acetate buffer $(\mathrm{pH} 5 \cdot 5)$ was used, low activity was observed $\left(k_{\text {cat }} 10 \mathrm{~s}^{-1}\right)$. Growth was also observed on this substrate. Dimethyl sulfone and 


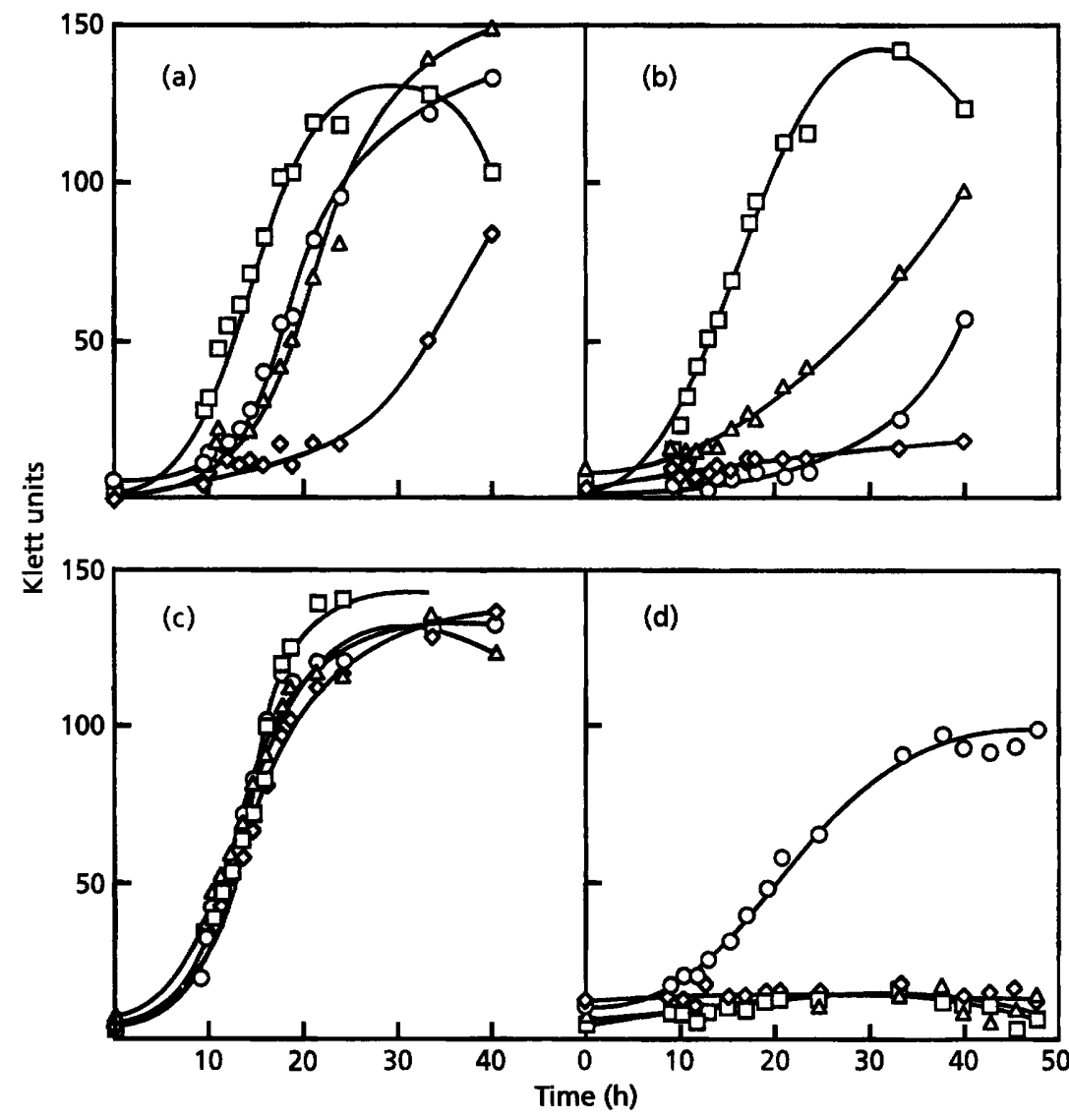

Fig. 3. Growth of wild-type $E$. coli and selected mutants on $\mathrm{S}$ - and $\mathrm{N}$-oxide substrates. Cells were grown in $160 \mathrm{ml}$ sidearm Klett flasks at $30^{\circ} \mathrm{C}$ on a stirred water bath. (a) MC4100 wild-type; (b) DSS401 $\triangle$ dmsABC; (c) LCB128torA; (d) DSS501 $\triangle d m s A B C$ torA. Terminal electron acceptors were used as follows: $70 \mathrm{mM}$ TMAO ( $\square) ; 30 \mathrm{mM}$ DMSO $(\diamond) ; 70 \mathrm{mM}$ 3-carboxypyridine $N$-oxide (O); $25 \mathrm{mM}$ 4-methylpyridine $\mathrm{N}$-oxide $(\Delta)$. Growth readings were taken as necessary with a KlettSummerson spectrophotometer equipped with a no. 66 filter, using minimal medium as a blank.

triethanolamine borate are substrates with $k_{\text {cat }}$ values of 12.8 and $4.2 \mathrm{~s}^{-1}$, respectively. A number of additional compounds were examined, but triethylamine $N$-oxide picrate, $\mathrm{K}_{2} \mathrm{CrO}_{4}, \mathrm{NaSeO}_{3}$, 5-chlorofurazan 3-oxide, 4 nitropyridine $N$-oxide and 4-nitroquinoline $N$-oxide accept electrons directly from $\mathrm{BVH}^{+}$, and thus could not be tested as substrates of DmsABC.

\section{Inhibition of DmsABC activity}

Compounds that were found to be poor substrates were tested for their ability to act as inhibitors of Dms ABC activity with TMAO as substrate. Because TMAO has a high $K_{\mathrm{m}}$, non-substrates would not need to have particularly low $K_{\mathrm{i}}$ values to inhibit enzyme activity. Dibutyl sulfoxide, DL-methyl(phenylsulfinyl)acetate, diphenyl sulfoxide, 2 -mercaptopyridine $N$-oxide, triethanolamine borate, chlorate, and 2-carboxypyridine $N$-oxide were not able to inhibit DmsABC activity. Biotin sulfoxide (33.5\% inhibition) and dimethyl sulfone $(12.4 \%$ inhibition) were found to be weak inhibitors of DmsABC activity. 3Carboxypyridine, the product of 3-carboxypyridine $N$ oxide reduction, was a poor inhibitor $(27 \cdot 3 \%)$.

\section{Growth inhibition by $\mathbf{S}$ - and $\mathbf{N}$-oxides}

It is possible that DmsABC may detoxify various $S$ - and $N$-oxides encountered in the environment, providing a selective advantage for the organism. We determined the toxicity of our collection of substrates to anaerobic growth of $E$. coli. Under the conditions described in Methods, most DmsABC substrates were not toxic to anaerobically growing $E$. coli (Tables 1 and 2). However, diphenyl sulfoxide, hydroxylamine - a protein modifier - and dimethyldodecylamine $N$-oxide - a detergent did cause zones of clearing around the substrate-soaked filters.

\section{Ability of $\mathbf{S}$ - and $\boldsymbol{N}$-oxides to act as terminal electron acceptors}

Many of the substrates' were able to support anaerobic growth of $E$. coli with glycerol as carbon and energy source (Tables 1 and 2). Most of the $N$-oxides tested could be used by $E$. coli as a terminal electron acceptor for anaerobic growth. Exceptions were 2-mercaptopyridine, 4-phenylpyridine, 4-nitropyridine and 3 $\alpha$-hydroxylbenzylpyridine $N$-oxides. Dimethyldodecylamine $N$-oxide inhibited anaerobic growth, presumably due to its detergent properties. The $S$-oxide compounds reduced by Dms ABC were able to support anaerobic growth, whereas those which were not reduced by DmsABC did not support growth.

Fig. 3(a) shows anaerobic growth curves of $E$. coli MC4100 grown on selected $S$ - and $N$-oxides. TMAO, 3carboxypyridine $N$-oxide and 4-methylpyridine $N$-oxide supported essentially identical growth rates, and these were comparable to growth rates with fumarate and 
pyridine $\mathrm{N}$-oxide as terminal acceptor (data not shown). MC4100 grew well on DMSO, but a longer lag preceded exponential growth. Stationary phase was reached in about $20 \mathrm{~h}$. Tetramethylene sulfoxide supported very limited growth (data not shown).

As reported previously (Sambasivarao \& Weiner, 1991a), E. coli DSS401, with the $d m s A B C$ operon deleted, grew well on TMAO, whereas no growth was observed on DMSO. This strain exhibited slower growth on 3carboxypyridine $\mathrm{N}$-oxide and 4-methylpyridine $\mathrm{N}$-oxide (Fig. 3b). E. coli LCB128, lacking the tor $A$ gene, grew well on all the substrates tested (Fig. 3c). E. coli lacking both $\operatorname{tor} A$ and $d m s A B C$ (DSS501) was unable to grow on sulfoxides and TMAO, but, surprisingly, maintained the ability to grown on 3-carboxypyridine $N$-oxide (Fig. 3d), pyridine $\mathrm{N}$-oxide and 3 -hydroxypyridine $\mathrm{N}$-oxide (data not shown). These results indicate that an alternative terminal reductase which conserves the redox energy of these pyridine $N$-oxides must be present in $E$. coli. This alternative terminal reductase does not appear to be a secondary activity of DmsABC or TorA, as this enzyme possesses a different substrate specificity.

\section{DISCUSSION}

We conclude that: (i) DmsABC has a very broad substrate specificity, and analysis of the data gives us a better understanding of the parameters which affect substrate binding and turnover; (ii) $K_{\mathrm{m}}$ values vary 470 -fold, while $k_{\text {cat }}$ values vary only 20 -fold, implicating $K_{\mathrm{m}}$ as the major determinant of $k_{\text {cat }} / K_{\mathrm{m}}$ values; (iii) DmsABC plays an important role in the utilization of $S$-and $N$-oxides; (iv) we have determined that there is another, as yet unidentified, terminal reductase that is capable of utilizing a subset of these compounds.

Two classes of $S$ - and $N$-oxide reductases have been identified (Iobbi-Nivol et al., 1996). One class has broad substrate specificity, and includes the periplasmic DMSO/ TMAO reductases of Rhodobacter sphaeroides and Rhodobacter capsulatus (McEwan et al., 1987; Satoh \& Kurihar, 1987). The second class has much more limited substrate specificity, and includes the TMAO reductases of Shewanella and E. coli (Clarke \& Ward, 1988; Iobbi-Nivol et al., 1996). DmsABC appears to be most similar to the Rhodobacter enzymes. Although the substrate specificity of DmsABC overlaps with TorA, the poorest DmsABC substrates are the best TorA substrates, and vice versa. This may allow these proteins to play complementary roles in the cell.

If we compare all the substrates solely on the basis of $k_{\text {cat }}$, we can identify three compounds (TMAO, 4-methylmorpholine $\mathrm{N}$-oxide and 3-hydroxypyridine $\mathrm{N}$-oxide) with substantially higher $k_{\text {cat }}$ values than all the other compounds tested. These compounds also have the highest $K_{\mathrm{m}}$ values, and therefore relatively poor $k_{\text {cat }} / K_{\mathrm{m}}$ values, suggesting that they are poor substrates. This is obviously not the case, as cells grow well using these compounds as terminal electron acceptors. Most substituted pyridine $N$-oxides have $k_{\text {cat }}$ values between 200 and $300 \mathrm{~s}^{-1}$, and sulfoxides have $k_{\text {cat }}$ values between 60 and $120 \mathrm{~s}^{-1}$. A very large range of $K_{\mathrm{m}}$ values was observed for these compounds, indicating that substrate affinity has a primary role in determining enzyme specificity.

Redox potential would be expected to affect $k_{\text {cat }}$ much more than $K_{\mathrm{m}}$. Pyridine $N$-oxides have lower redox potentials and are more difficult to reduce than aliphatic $N$-oxides, because the electrons from the oxygen are in resonance with the aromatic ring, stabilizing the unstable $\mathrm{N}-\mathrm{O}$ bond (Ochaiai, 1953, 1967). It is possible that the lower redox potentials of pyridine $N$-oxides could be an influencing factor in the lower $k_{\text {cat }}$ values observed for these compounds.

Reduction of $\mathrm{N}$-oxides has been suggested to occur after protonation (Kubota \& Miyazaki, 1962; Ochaiai, 1967). As aliphatic $N$-oxides are more easily protonated than pyridine $N$-oxides (Kubota \& Miyazaki, 1962), it is possible that this factor may also contribute to the higher $k_{\text {cat }}$ values observed for aliphatic $N$-oxides.

A pattern is observed when the $K_{\mathrm{m}}$ values are examined. The $K_{\mathrm{m}}$ values are approximately equivalent for pyridine $\mathrm{N}$-oxide and pyridine $\mathrm{N}$-oxides substituted in the 2 and 3 position. Pyridine $\mathrm{N}$-oxides substituted in the 4 position have higher $K_{\mathrm{m}}$ values. Carboxy-substituted pyridine $N$ oxides do not follow the rule above, and are not good substrates. This is presumably due to their negative charge.

The $K_{\mathrm{m}}$ values for the pyridine $N$-oxides and sulfoxides are observed to be lower than for the aliphatic $N$-oxides. This may be for steric reasons, suggesting that the enzyme may be willing to accept compounds with two substituents more easily than those with three substituents. The only aliphatic $N$-oxide that does not follow this rule is dimethyldodecylamine $\mathrm{N}$-oxide, and it is possible that the lower $K_{\mathrm{m}}$ value observed could be due to additional contacts between the dodecyl sidechain and the enzyme, or possibly due to partitioning of substrate into Triton X$100 /$ protein micelles.

Compact sulfoxides (DMSO and tetramethylene sulfoxide) or those with one extended substituent are accommodated by the enzyme (DL-methionine sulfoxide and DL-methyl phenyl sulfoxide). However, those that are bulky and those with two extended substituents are not [dibutyl sulfoxide, DL-methyl(phenylsulfinyl)acetate and diphenyl sulfoxide]. This agrees with X-ray structures of molybdopterin- and tungstopterin-containing aldehyde oxidoreductases, and molybdopterin-containing DMSO reductase from $R$. spheroides, all of which show that the active site is accessible only through a narrow tunnel (Chan et al., 1995; Romao et al., 1995; Schindelin et al., 1996).

We have demonstrated that E. coli has the ability to use a wide variety of $S$ - and $N$-oxides as terminal electron acceptors, resulting in anaerobic growth in the presence of glycerol. TMAO has widespread natural occurrence in nature as an osmostabilizer in salt water fish, and DMSO is found in sea water as part of the global sulfur cycle (Barrett \& Kwan, 1985; Kelly \& Baker, 1990; Kiene \& 
Bates, 1990). Many of these compounds are also manmade. DMSO is used as a solvent and is found as an effluent from wood pulp mills (Wood, 1981). Substituted pyridine $\mathrm{N}$-oxides are found as soil contaminants, in crude petroleum and in coal tar, and are used as organic solvents and drugs (Shukla, 1984). DmsABC is a key enzyme in utilization of these compounds, as shown by the work reported herein. The presence of DmsABC in $E$. coli may result in a selective advantage for the organism to enable it to use a wide variety of $S$ - and $N$-oxides as they are encountered in the environment, including utilizing $S$ oxide drugs found in the intestine (Lee \& Renwick, 1995).

\section{ACKNOWLEDGEMENTS}

We would like to acknowledge Dr Jed Harrison, Dr Gerard Giordano, Janine Pommier, Dr Richard Rothery, Dr Raymond Turner and Pavel Badalov for providing pertinent scientific information, and Gillian Shaw and Dawn Dimaculangan for providing technical assistance. This work was supported in part by the Medical Research Council of Canada through Medical Research Council Grant PG-11440 (J.H.W.). The Alberta Heritage Foundation for Medical Research, and the National Sciences and Engineering Research Council have provided graduate studentships for J. L. S.-G.

\section{REFERENCES}

Barrett, E. L. \& Kwan, H. S. (1985). Bacterial reduction of trimethylamine oxide. Annu Rev Microbiol 39, 131-149.

Bilous, P. T. \& Weiner, J. H. (1985a). Dimethyl sulfoxide reductase activity by anaerobically grown Escherichia coli. J Bacteriol 162, 1151-1155.

Bilous, P. T. \& Weiner, J. H. (1985b). Proton translocation coupled to dimethyl sulfoxide reduction in anaerobically grown Escherichia coli HB101. J Bacteriol 163, 369-375.

Bilous, P. T., Cole, S. T., Anderson, W. F. \& Weiner, J. H. (1988). Nucleotide sequence of the $d m s A B C$ operon encoding the anaerobic dimethylsulphoxide reductase of Escherichia coli. Mol Microbiol 2, 785-795.

Boyer, H. W. \& Roulland-Dussoix, D. (1969). A complementary analysis of the restriction and modification of DNA in Escherichia coli. J Mol Biol 41, 459.

Cammack, R. \& Weiner, J. H. (1990). Electron paramagnetic resonance spectroscopic characterization of dimethyl sulfoxide reductase of Eschericbia coli. Biocbemistry 29, 8410-8416.

Casadaban, M. J. (1976). Transposition and fusion of the lac genes to selected promoters in Escherichia coli using bacteriophage lambda and Mu. Mol Biol 104, S41-S55.

Cecchini, G., Ackrell, B. A. C., Deshler, J. O. \& Gunsalus, R. P. (1986). Reconstitution of quinone reduction and characterization of Escherichia coli fumarate reductase activity. $J$ Biol Chem 261, 1808-1814.

Chan, M. K., Mukund, S., Kletzin, A., Adams, M. W. W. \& Rees, D. C. (1995). Structure of a hyperthermophilic tungstopterin enzyme, aldehyde ferredoxin oxidoreductase. Science 267, 1463-1469.

Clarke, G. \& Ward, B. (1988). Purification and properties of trimethylamine $N$-oxide reductase from Shewanella sp. NCMB 400. $J$ Gen Microbiol 134, 379-386.

Fersht, A. (1977). The basic equations of enzyme kinetics; and enzyme-substrate complementarity and theories of enzyme catalysis. In Envyme Structure and Mechanism, pp. 84-102, 244-271. San Francisco: W. H. Freeman.

lobbi-Nivol, C., Pommier, J., Simala-Grant, J., Mejean, V. \& Giordano, G. (1996). High substrate specificity and induction characteristics of trimethylamine $\mathrm{N}$-oxide reductase of Escberichia coli. Biocbim Biophys Acta 1294, 77-82.

Kelly, D. P. \& Baker, S. C. (1990). The organosulphur cycle: aerobic and anaerobic processes leading to turnover of $C_{1}$ sulphur compounds. FEMS Microbiol Rev 87, 241-246.

Kiene, R. P. \& Bates, T. S. (1990). Biological removal of dimethylsulphide from sea water. Nature 345, 702-705.

Kubota, T. \& Miyazaki, H. (1962). Polarography of pyridine $N$ oxide and its alkyl derivatives. Bull Chem Soc Jpn 35, 1549-1551.

Laemmli, U. K. (1970). Cleavage of structural proteins during the assembly of the head of bacteriophage 'T4. Nature 227, 680-685.

Lee, S. C. \& Renwick, A. G. (1995). Sulfoxide reduction by rat intestinal flora and by Escherichia coli. Biochem Pharmacol 49, $1567-1576$.

Lemire, B. D., Robinson, J. J. \& Weiner, J. H. (1982). Identification of membrane anchor polypeptides of Eschericbia coli fumarate reductase. J Bacteriol 152, 1126-1131.

McEwan, A. G., Wetzstein, H. G., Meyer, O., Jackson, J. B. \& Ferguson, S. J. (1987). The periplasmic nitrate reductase of Rhodobacter capsulatus; purification, characterisation and distinction from a single reductase for trimethylamine- $N$-oxide, dimethylsulphoxide and chlorate. Arch Microbiol 147, 340-345.

Markwell, M. A. D., Haas, S. M., Bieber, L. L. \& Tolbert, N. E. (1978). A modification of the Lowry procedure to simplify protein determination in membrane and lipoprotein samples. Anal Biochem 87, 206-210.

Mejean, V., lobbi-Nivol, C., Lepelletier, M., Giordano, G., Chippaux, M. \& Pascal, M.-C. (1994). Trimethylamine $N$-oxide anaerobic respiration in Eschericbia coli: involvement of the tor operon. Mol Microbiol 11, 1169-1179.

Melville, D. B. (1954). Biotin sulfoxide. J Biol Chem 208, 495-501. Neugebauer, J. M. (1990). Detergents: an overview. Methods Envymol 182, 239-253.

Neumann, S. \& Simon, H. (1984). On a non-pyridine nucleotidedependent 2-oxo-acid reductase of broad substrate specificity from two Proteus species. FEBS Lett 167, 29-32.

Ochaiai, E. (1953). Recent Japanese work on the chemistry of pyridine 1-oxide and related compounds. J Org Chem 18, 534-551.

Ochaiai, E. (1967). Aromatic Amine Oxides, pp. 6-17, 91-97. Amsterdam: Elsevier.

Oren, A. \& Truper, H. G. (1990). Anaerobic growth of halophilic archaebacteria by reduction of dimethyl sulfoxide and trimethylamine $N$-oxide. FEMS Microbiol Lett 70, 33-36.

Pascal, M.-C., Burini, J.-F. \& Chippaux, M. (1984). Regulation of the trimethylamine $N$-oxide (TMAO) reductase in Escherichia coli: analysis of tor: Mud1 operon fusion. Mol Gen Genet 195, 351-355.

Romao, M. J., Archer, M., Moura, I., Moura, J. J. G., LeGall, J., Engh, R., Schneider, M., Hof, O. \& Huber, R. (1995). Crystal structure of the xanthine oxidase-related aldehyde oxido-reductase from $D$. gigas. Science 270, 1170-1176.

Rothery, R. A. \& Weiner, J. H. (1991). Alteration of the iron-sulfur cluster composition of Escherichia coli dimethyl sulfoxide reductase by site-specific mutagenesis. Biocbemistry 30, 8296-8305.

Rothery, R. A. \& Weiner, J. H. (1993). Topological characterization of Eschericbia coli DMSO reductase by electron paramagnetic 
spectroscopy of an engineered [3Fe-4S] cluster. Biocbemistry 32, 5855-5861.

Rothery, R. A., Simala-Grant, J. L., Johnson, J. L., Rajagopalan, K. V. \& Weiner, J. H. (1995). Association of molybdopterin guanine dinucleotide with Escherichia coli dimethyl sulfoxide reductase: effect of tungstate and a mob mutant. J Bacteriol 177, 2057-2063.

Sambasivarao, D. \& Weiner, J. H. (1991a). Differentiation of the multiple $S$ - and $N$-oxide reducing activities of Escherichia coli. Curr Microbiol 23, 105-110.

Sambasivarao, D. \& Weiner, J. H. (1991b). Dimethyl sulfoxide reductase of Escberichia coli: an investigation of function and assembly by use of in vivo complementation. $J$ Bacteriol 173, 5935-5943.

Sambrook, J., Fritsch, E. F. \& Maniatis, T. (1989). Molecular Cloning: a Laboratory Manual. Cold Spring Harbor, NY: Cold Spring Harbor Laboratory.

Satoh, T. \& Kurihar, F. N. (1987). Purification and properties of dimethyl sulfoxide reductase containing a molybdenum cofactor from a photodenitrifier $R$ bodopseudomonas sphaeroides f.s. denitrificans. $J$ Biocbem 102, 191-197.

Schindelin, H., Kisker, C., Hilton, J., Rajagopalan, K. V. \& Rees, D. C. (1996). Crystal structure of DMSO reductase: redox linked changes in molybdopterin coordination. Science 272, 1615-1621.

Shukla, O. P. (1984). Microbial transformation of pyridine derivatives. J Sci Ind Res 43, 98-116.

Silvestro, A., Pommier, J. \& Giordano, G. (1988). The inducible trimethylamine $N$-oxide reductase of Escherichia coli K12: bio- chemical and immunological studies. Biocbim Biopbys Acta 954, $1-13$.

Silvestro, A., Pommier, J., Pascal, M.-C. \& Giordano, G. (1989). The inducible trimethylamine $N$-oxide reductase of Eschericbia coli K12: its localization and inducers. Biochim Biopbys Acta 999, 208-216.

Trieber, C. A., Rothery, R. A. \& Weiner, J. H. (1994). Multiple pathways of electron transfer in dimethyl sulfoxide reductase of Escherichia coli.J Biol Chem 269, 7103-7109.

Weiner, J. H., Maclssac, D. P., Bishop, R. E. \& Bilous, P. T. (1988). Purification and properties of Escherichia coli dimethyl sulfoxide reductase, an iron-sulfur molybdoenzyme with broad substrate specificity. $J$ Bacteriol 170, 1505-1510.

Weiner, J. H., Rothery, R. A., Sambasivarao, D. \& Trieber, C. A. (1992). Molecular analysis of dimethyl sulfoxide reductase: a complex iron-sulfur molybdoenzyme of Escherichia coli. Biochim Biophys Acta 1102, 1-18.

Wood, P. M. (1981). The redox potential for dimethyl sulphoxide reduction to dimethyl sulphide. FEBS Lett 124, 11-14.

Yamamoto, I., Okubo, M. \& Ishimoto, M. (1986). Further characterization of trimethylamine $N$-oxide reductase from Escherichia coli a molybdoprotein. $J$ Biocbem 99, 1773-1779.

Yamamoto, I., Hohmura, M. \& Ishimoto, M. (1989). A novel gene, torB, for trimethylamine $N$-oxide reductase in Escherichia coli. J Gen Appl Microbiol 35, 95-105.

Received 2 May 1996; revised 15 July 1996; accepted 17 July 1996. 